\title{
Desacralizar la cultura: el patrimonio como agnosticismo como principio metodológico
}

Juan de Dios López López | Laboratorio de Estudios Interculturales, Universidad de Granada

URL de la contribución <www.iaph.es/revistaph/index.php/revistaph/article/view/3896>

\section{A JL, en recuerdo de cierta conversación nocturna}

Cuando en 2001 el gobierno talibán afgano ordenó y ejecutó la destrucción de los budas de Bamiyan, se alzaron múltiples voces denunciando ese atentado contra la "Cultura", contra un patrimonio cultural mundial. Las primeras explicaciones que se esbozaron señalaron la oposición del islamismo talibán al budismo y al resto de religiones como el principal motivo de la destrucción de las estatuas. Sin embargo, hubo también quien advirtió de que aquel acto iconoclasta no era contra el budismo, ni contra ninguna otra religión en el sentido tradicional, sino que era una acción dirigida contra la veneración secular a la obra de arte y al patrimonio (GONZÁLEZ ALCANTUD, 2012: 20-24) y un mensaje para la Unesco, el Vaticano de "la iglesia mundial del patrimonio" (BRUMANN, 2014: 183), que se erigió como principal defensor de las imágenes.

La comparación del patrimonio con una suerte de religión laica, en todo caso, no es una novedad y abunda en los estudios críticos sobre los procesos de patrimonialización. Una religión que contaría con una casta sacerdotal propia (gestores culturales, expertos en patrimonio, museólogos, etc.) capaces de conectar a los fieles con el elemento sagrado: la "Cultura", que habría desplazado a la idea de Dios en las sociedades secularizadas (PRATS, 2005; HERNÁNDEZ I MARTí, 2008; LÓPEZ LÓPEZ, 2016a). Siguiendo esta concatenación alegórica, Christoph Brumann (2014) distingue entre "creyentes del patrimonio", quienes estarían convencidos de la sacralidad de la "Cultura" y de su valor inherente, y "ateos patrimoniales", quienes desde una perspectiva deconstruccionista, considerarían el patrimonio como el resultado de una determinada manipulación sobre elementos arbitrariamente seleccionados. Entre esos dos polos, Brumann propone el agnosticismo como principio metodológico en el estudio y comprensión del fenómeno patrimonial. Ante la imposibilidad de estudiar empíricamente las supuestas cualidades sagradas de cualquier elemento patrimonial, lo mejor es centrarse en cómo tales elementos son usados y experimentados por distintos grupos y cómo, mediante la atribución de determinados valores, llegan a situarlos en un espacio sacro.

En palabras del propio Brumann, "un estudio agnóstico del patrimonio no sostiene a priori que el patrimonio es un significante vacío, un atributo completamente arbitrario y socialmente determinado, sino que se toma seriamente la experiencia y las creencias patrimoniales de la gente" (BRUMANN, 2014, 180, traducción propia). En este sentido, se distancia de las aproximaciones al patrimonio hechas desde una postura radicalmente atea 0 , podríamos llamarlas, simplificando, "anti-patrimonio". Pero también se aleja de las perspectivas creyentes o "pro-patrimonio", aquellas que le atribuyen a los elementos patrimonializados valores intrínsecos y cualidades morales positivas e inherentes.

De lo que se trataría, más que de dilucidar las propiedades formales del objeto patrimonial, es de estudiar los procesos de patrimonialización: los procesos mediante los cuales un determinado elemento (ya sea calificado como material o inmaterial) llega a ser considerado y reconocido como patrimonio (institucionalmente o no) por parte de determinados grupos. Estudiar los procesos de patrimonialización también nos obligaría a tener en cuenta los intereses de los grupos, instituciones o individuos que impulsan el proceso, las oposiciones que suscita y las consecuencias de tal reconocimiento.

Pero, como ya advirtiera hace tiempo Francisco Cruces, también desde una perspectiva agnóstica, "de nada nos serviría profanar las vitrinas si a cambio sacralizamos 


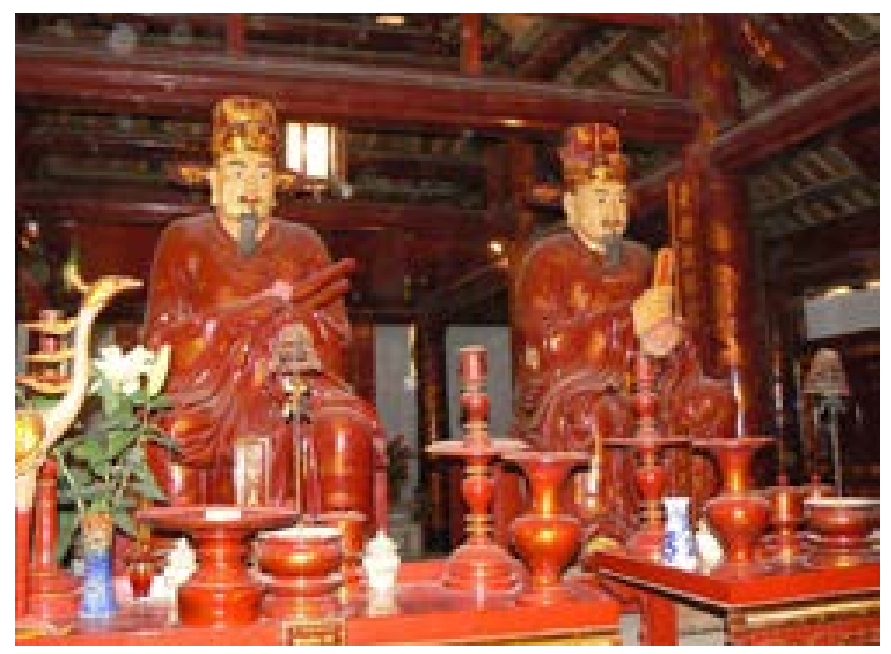

Templo budista en Hanoi, Vietnam

los textos y las teorías" (CRUCES, 1998: 81). Si lo que se pretende es fomentar la participación democrática en la toma de decisiones sobre el patrimonio, frente a la tecnocracia imperante en los procesos institucionales de patrimonialización, se debería apostar por un patrimonio vivo, en uso, y no por el patrimonio vitrificado y a disposición tan solo de los expertos al que conducen ciertas prácticas conservacionistas. Como recomienda José Antonio González Alcantud (2016: 38-39), la sociedad actual debería "relajar su escrupulosa vigilancia patrimonial apostando más por la conservación de la memoria social y desarrollando el patrimonio vivo. (...) la cultura en general debe ser desacralizada de sus actuales ataduras y compromisos, dejándola volar libre del corsé hieratizador del conservacionismo, ergo conservadurismo".

La importancia de la conservación del patrimonio (en su forma original o auténtica, se dice a veces) está discursivamente asociada a la necesidad de salvaguardar los valores que supuestamente portan los elementos patrimonializados. La cuestión de los valores siempre está presente en cualquier aproximación al patrimonio por lo que debe aclararse muy bien de qué tipo de valores se está hablando. Cuando en cumplimiento de la Ley de la memoria histórica comenzaron a retirarse los símbolos del nacional-catolicismo, algunos nostálgicos del

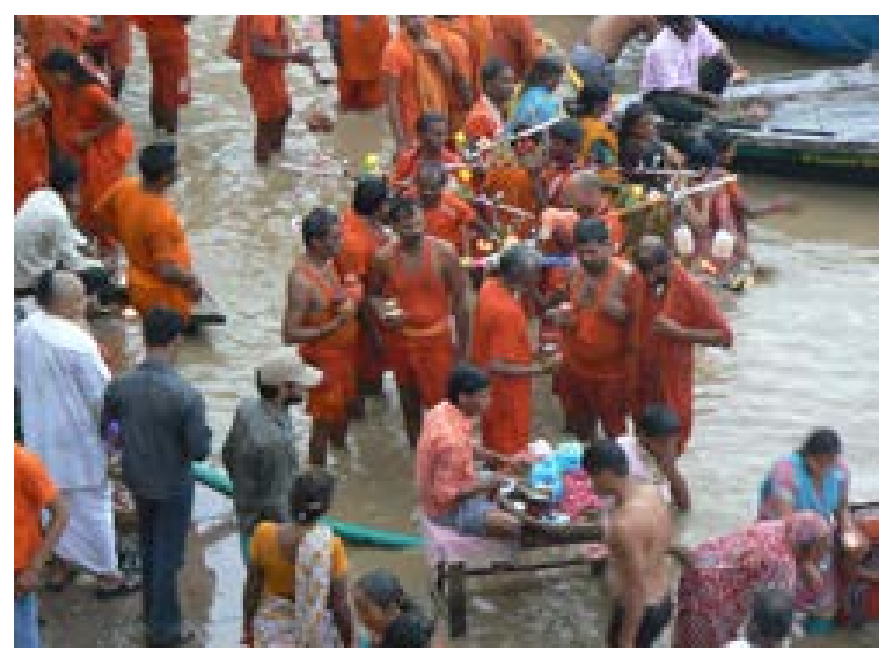

Baños rituales en el Ganges. Benarés, India | fotos Martín J. Fernández Muñoz

franquismo se opusieron aduciendo el valor histórico y patrimonial de tales obras. El argumento del valor histórico o cultural, no obstante, es esgrimido con frecuencia por gentes provenientes de cualquier punto del espectro ideológico, con objeto de impulsar determinados procesos de patrimonialización o para oponerse, como en el caso de los nostálgicos del régimen de Franco, a determinados procesos de des-patrimonialización. Por supuesto cualquier vestigio del pasado puede tener un valor histórico, en el sentido de que puede ayudar a mejorar nuestra comprensión sobre una determinada época o sobre el discurrir de los tiempos, pero esto no quiere decir que sea moral o éticamente positiva su salvaguarda y conservación.

Dicho de forma muy simple, cualquier guerra tiene un indudable valor histórico, pero eso no quiere decir que debamos conmemorar y ensalzar los conflictos bélicos; baste con documentar su memoria y tratar de evitarlos en lo posible. A menudo se confunde el valor de determinados objetos, en tanto que útiles para el desarrollo de determinados estudios y disciplinas académicas, con una categoría moral. A mi juicio, como ya señalé en un debate anterior en estas mismas páginas (LÓPEZ LÓPEZ, 2016b), la atribución de valores patrimoniales a un determinado objeto será siempre una tarea colectiva 


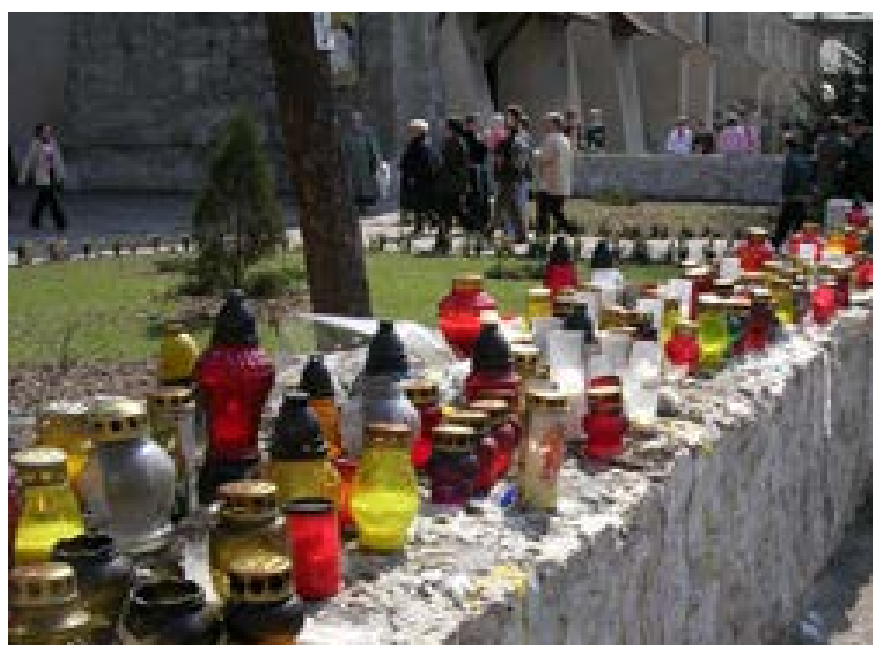

Homenaje en Cracovia (Polonia) al papa Wojtyła tras su fallecimiento

y política y, por lo tanto, los procesos de patrimonialización serán siempre un espacio de conflicto que, en los casos exitosos, se resolverá mediante acuerdos frágiles y precarios entre las partes.

\section{NOTA}

1. Uso aquí el vocablo "Cultura", en mayúscula y entrecomillado, para referirme al uso que le suelen dar a este término las administraciones públicas y las industrias "culturales" y que generalmente hace referencia a sus ámbitos de gestión, básicamente, las producciones artísticas y el patrimonio cultural. De este modo, quiero evitar confusiones entre este uso del término y los usos del término cultura, en minúsculas y sin comillas, que se hace desde la antropología y que, sin entrar en complejos ejercicios de definición, abarca cualquier forma de acción social y producción humana. Como provocativa y acertadamente ha dicho Ángel Díaz de Rada (2010: 114), para los antropólogos tan cultural es la música de Shostakovitch como la acción de la persona que vende las entradas para uno de sus conciertos.

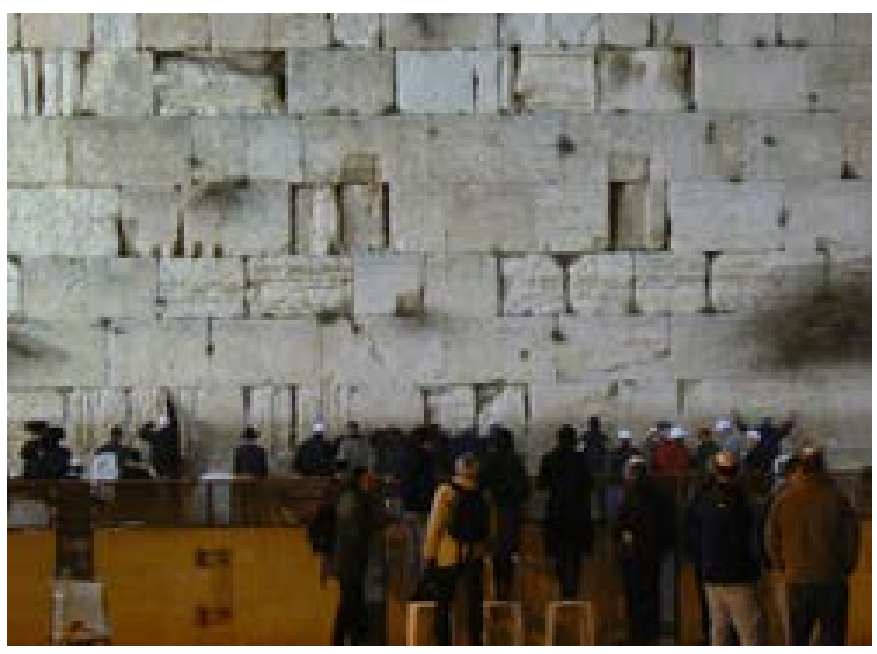

Muro de las Lamentaciones en la explanada de las Mezquitas en Jerusalén | fotos Martín J. Fernández Muñoz

\section{BIBLIOGRAFÍA}

- BRUMANN, C. (2014) Heritage agnosticism: A third path for the study of cultural heritage. Social Anthropology, 22(2), 2014, pp. 173-188

- CRUCES VILLALOBOS, F. (1998) Problemas en torno a la restitución del patrimonio. Una visión desde la antropología. Política y Sociedad, 27, 1998, pp. 77-87

- DíAZ DE RADA, A. (2010) Cultura, antropología y otras tonterías. Madrid: Trotta, 2010

- GONZÁLEZ ALCANTUD, J. A. (2012) El malestar en la cultura patrimonial. La otra memoria global. Barcelona: Anthropos, 2012

- GONZÁlez ALCANTUD, J. A. (dir.) (2016) La Alhambra, mito y vida 1930-1990. Tientos de memoria oral y antropología de un Patrimonio de la Humanidad. Granada: Universidad de Granada, 2016

- HERNÁNDEZ I MARTí, G. M. (2008) Un zombi de la modernidad: el patrimonio cultural y sus límites. La Torre del Virrey: Revista de Estudios Culturales, 5, 2008, pp. 27-38

- LÓPEZ LÓPEZ, J. D. (2016a) La cultura sacralizada. Estudios sobre patrimonio y turismo en la provincia de Granada. Tesis doctoral, Universidad de Granada, 2016

- LÓPEZ LÓPEZ, J. D. (2016b) El patrimonio como constructo político y su potencial reflexivo. Revista $\mathrm{PH}, \mathrm{n} .{ }^{\circ} 90$, octubre 2016, pp. 218-219

- PRATS, L. (2005) Concepto y gestión del patrimonio local. Cuadernos de Antropología Social, 21, 2005, pp. 17-35 